|| Print ISSN: 2589-7837 || Online ISSN: 2581-3935 ||

International Journal of Medical Science and Diagnosis Research (IJMSDR)

Available Online at www.ijmsdr.com

NLM (National Library of Medicine ID: 101738824)

Original Research Article

Volume 5, Issue 9; September:2021; Page No. 17-23

\title{
Correlation of Lead Exposure on Calcium Metabolism, Vitamin D3 in Battery Manufacturing Workers
}

\author{
Kiran Malik ${ }^{1}$, Savita Rathore ${ }^{2}$, Mahakal Chandel ${ }^{3}$ \\ ${ }^{1}$ PhD. Scholar, IMCHRC, Indore, MP \\ ${ }^{2}$ Department of Biochemistry, AIMS, Dewas, MP \\ ${ }^{3}$ Academic Registrar, Malwanchal University, Indore, MP
}

Conflicts of Interest: Nil

Corresponding author: Kiran Malik

DOI: https://doi.org/10.32553/ijmsdr.v5i9.850

\section{Abstract:}

Background: Chronic lead exposure from the lead-acid-battery manufacturing process has been linked to a variety of health effects, including dental health, cardiovascular disease risk, Matrix-gamma-carboxy glutamic acid protein (MGP) polymorphism, oxidative stress, immunological, genotoxicity, reproductive, neuropsychological, and pteridine metabolism with neurotransmitters synthesized.

Aim of the Work: effects of lead exposure on calcium metabolism in battery workers.

Subjects and Methods: The present study will be conducted in Department of Biochemistry, Index Medical College and research center, Indore. A total of 100 lead exposed battery workers and 100 aged (20-60 yr) matched non lead exposed controls. Blood sample was withdrawn from the anticubital vein and centrifuged to obtain serum after that serum was quantitatively analyzed for lead level, calcium, phosphorous and vitamin D3.

Result and Conclusion: In lead-exposed battery workers, correlation analysis revealed a strong negative connection between blood lead levels and serum vitamin D levels. Similarly, serum calcium levels were found to be inversely linked with blood lead levels.

Keywords: Battery workers, Lead

\section{Introduction:}

Lead poisoning has been the most widespread environmental health concern confronting humanity in recent years. Despite being a naturally occurring component of the earth's crust, lead does not become dangerous until it is extracted and turned into human-made items. When it comes into contact with humans, it is swiftly absorbed in blood and soft tissues and slowly absorbed in bones ${ }^{1}$.

Lead is also prevalent in locations where lead pipes are utilized for potable water supply, in addition to petroleum-related emissions. Furthermore, absorption of old leaded paint and glazes used in ceramics is linked to lead exposure in the home.
Lead contamination has not been managed and is intermittent in nations in the global south, particularly in India. Many previous studies have found that more than half of India's children have high blood lead levels (te $\mathrm{g} / \mathrm{dL})^{2}$.

Lead and its compounds have been linked to a variety of human health issues, including acute, sub-acute, and chronic occupational lead poisoning. Lead poisoning occurs as a result of lead manufacturing and usage activities, which are mostly linked to emissions from lead smelting plants, automobile emissions, and lead contamination of food or drinking water. 
Various studies have shown that the current lead acid battery manufacturing process, which involves various subsections such as lead oxide fabrication, grid casting, pasting, plate cutting, forming, charging, and assembly, is the primary source of lead danger today. Furthermore, hazardous substances such as lead oxide ( $\mathrm{PbO} 2)$, spongy lead $(\mathrm{Pb})$, and sulphuric acid are employed in this procedure (H2SO4). Workers are exposed to lead by inhalation, ingestion, and skin contact during these procedures. Lead accumulates in red blood cells, soft tissue (brain, kidney, and bone marrow), and mineralised tissue after it enters the body (bone \& teeth). Airborne lead toxicity is common in lead acid battery manufacturing sites, and it's linked to an increase in blood lead levels $(\mathrm{BLL})^{3}$.

Chronic lead exposure from the lead-acid-battery manufacturing process has been linked to a variety of health effects, including dental health, cardiovascular disease risk, Matrix-gammacarboxy glutamic acid protein (MGP) polymorphism, oxidative stress, immunological, genotoxicity, reproductive, neuropsychological, and pteridine metabolism with neurotransmitters synthesized ${ }^{4,5}$.

Lead poisoning can be acute, subacute, or chronic. The public is concerned about all of these toxins. The toxicokinetics of lead and the mechanism of poisoning have yet to be fully understood. Bivalent cations include lead, calcium, and zinc. At blood lead levels as low as $5 \mathrm{~g} / \mathrm{dL}$, lead absorption raises blood pressure, especially systolic blood pressure. However, nothing is known about genetic diversity in the risk of high blood pressure caused by lead ${ }^{6}$.

The present research was show the effects of lead exposure on calcium metabolism in battery workers"

\section{Material and Methods:}

The present study will be conducted in Department of Biochemistry, Index Medical College and research center, Indore. A total of 100 lead exposed battery workers and 100 aged (20-60 yr) matched non lead exposed controls. A Performa containing questionnaire as base line record (Performa enclosed) was filled prior to the blood specimen collection. All ethical measures were taken during the course of study. Blood sample was withdrawn from the anticubital vein and centrifuged to obtain serum after that serum was quantitatively analyzed for lead level, calcium, phosphorous and vitamin D3.

The mean ( \pm SD) blood lead level of test group (lead exposed battery workers) was compared with that of control group (non lead exposed controls) by ANOVA test. A p value of less than 0.05 was considered as significant.

\section{Results}

Table 1: Comparison of Blood lead level of LEBW and NLEC

\begin{tabular}{|l|l|l|l|}
\hline \multirow{2}{*}{ Variable } & LEBW & NLEC & \multirow{2}{*}{ p - Value } \\
\cline { 2 - 3 } & Mean \pm SD & Mean \pm SD & \\
\hline Blood lead level $\mu \mathrm{g} / \mathrm{dl}$ & $38.9 \pm 30.8$ & $11.2 \pm 12.5$ & 0.001 \\
\hline
\end{tabular}

LEBW $=$ lead exposed battery workers

NLEC $=$ Non lead exposed controls

Values in Mean \pm SD

$* \mathrm{p}<0.001$ (highly significant)

This was observed that the average (Mean \pm SD) Blood lead concentration that was found in the LEBW group was $38.9 \pm 30.8$ and in the NLEC group, it was $11.2 \pm 12.5$. The blood lead level was found significantly higher in LEBW group, in comparison to that in the (NELC group) control group, with a $p$ value of $<0.001$. However, one way anova of variance indicated that these differences in mean blood lead level among two groups were highly significant $(p<0.001)$. 


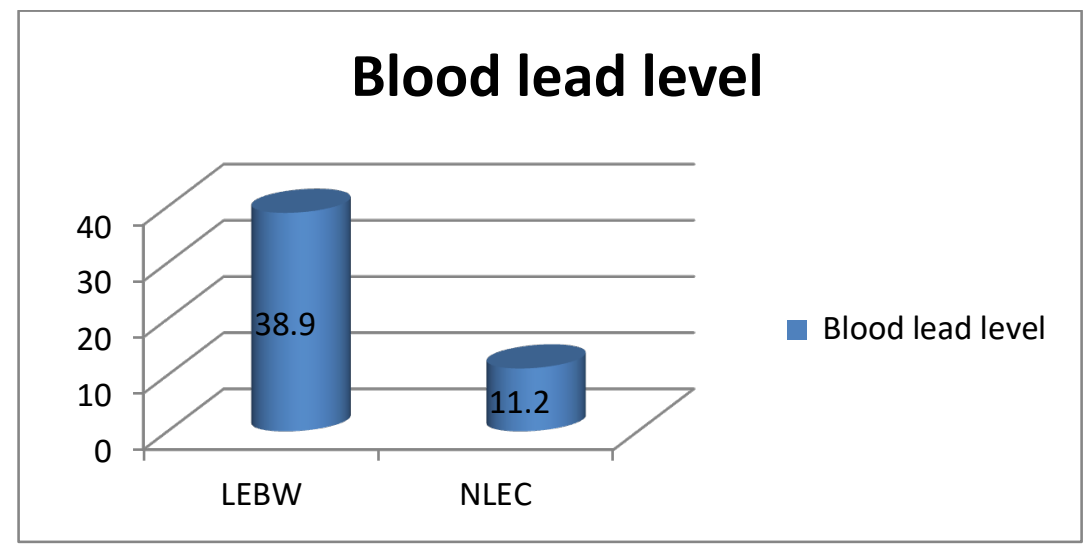

Figure 1: Comparison of blood lead level of control group and subject group, in the form of bar diagram.

Table 2: Comparison of Blood lead level of LEBW and NLEC in different age groups

\begin{tabular}{|l|l|l|l|}
\hline \multirow{2}{*}{ Age (Year) } & LEBW & NLEC & \multirow{2}{*}{ - Value } \\
\cline { 2 - 4 } & Mean \pm SD & Mean \pm SD & 0.001 \\
\hline $20-30$ & $35.0 \pm 34.0$ & $11.8 \pm 11.2$ & 0.001 \\
\hline $31-40$ & $39.8 \pm 26.9$ & $10.3 \pm 8.9$ & 0.001 \\
\hline $41-60$ & $47.7 \pm 28.6$ & $8.2 \pm 6.8$ & \\
\hline
\end{tabular}

LEBW $=$ lead exposed battery workers

NLEC $=$ Non lead exposed controls

Values in Mean \pm SD

$* \mathrm{p}<0.001$ (highly significant)

This was observed that the average (Mean \pm SD) Blood lead concentration in various age groups of LEBW group, that was found in LEBW in the age group of $31-40$ was $35.0 \pm 34.0$ and $41-60$ was $47.7 \pm 28.6$ showed significantly higher blood lead level as compare to age group $20-30$, it was $35.0 \pm 34.0$. The battery workers' blood lead levels were higher after a longer period of exposure. Thus, battery workers exposed for $>20$ years and between 10 and 20 years had significantly higher blood lead levels than those exposed for less than 10 years, with a $p$ value of 0.001 . However, a one-way anova of variance revealed that the differences in mean blood lead levels between exposure durations were very significant (p0.001).

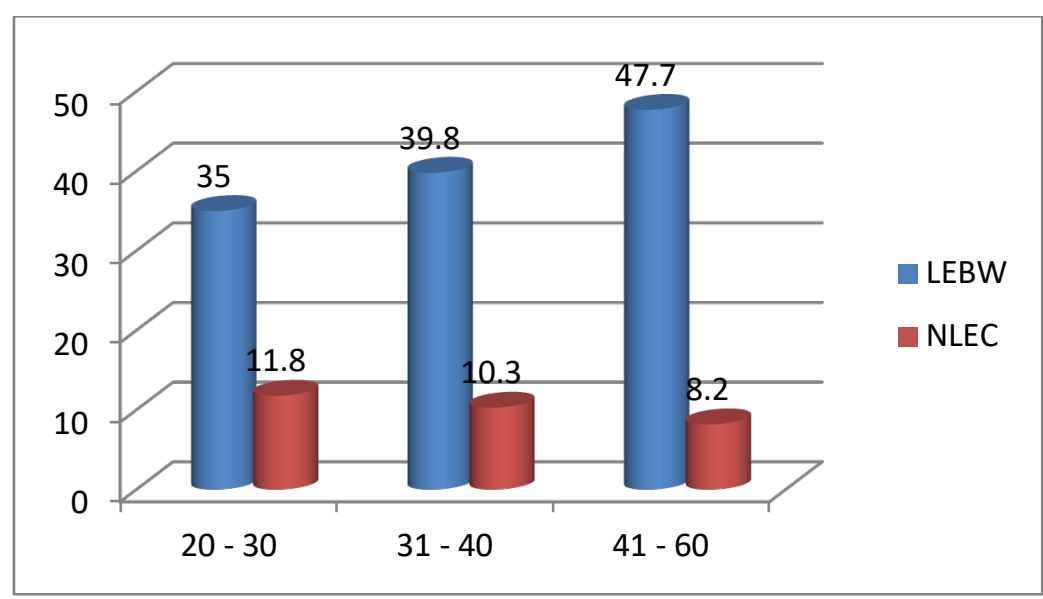

Figure 2: Comparison of blood lead level of control group and subject group, in different age groups, in the form of bar diagram 
Table 3: Comparison of Blood lead level of LEBW and NLEC in smoker and non-smoker

\begin{tabular}{|l|l|l|l|}
\hline \multirow{2}{*}{ Variable } & LEBW & NLEC & \multirow{2}{*}{ P - Value } \\
\cline { 2 - 4 } & Mean \pm SD & Mean \pm SD & \\
\hline Smoker & $41.7 \pm 31.7$ & $15.1 \pm 7.6$ & 0.001 \\
\hline Non-smoker & $32.8 \pm 29.9$ & $6.4 \pm 8.1$ & 0.001 \\
\hline
\end{tabular}

LEBW = lead exposed battery workers

NLEC $=$ Non lead exposed controls

Values in Mean \pm SD

$* \mathrm{p}<0.001$ (highly significant)

This was observed that the average (Mean \pm SD) Blood lead concentration in smoker and non-smokers of LEBW group, that was found in LEBW in the smokers was $41.7 \pm 31.7$ and non-smokers was $32.8 \pm$ 29.9. Smokers showed significantly higher blood lead level as compare to non-smokers in the battery workers, with a $p$ value of $<0.001$. However, one way anova of variance indicated that these differences in mean blood lead level among smokers and non-smokers is highly significant $(p<0.001)$.

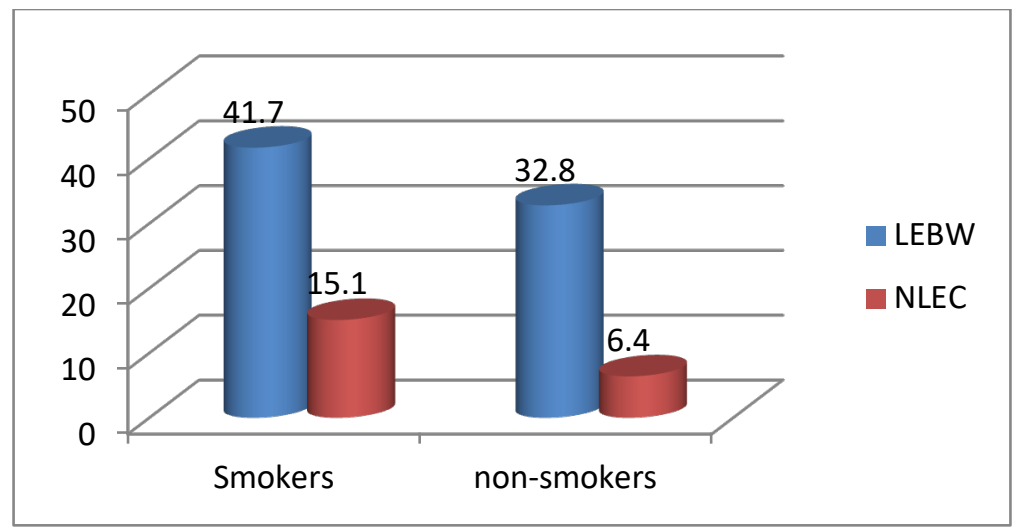

Figure 3: Comparison of Blood lead level of LEBW and NLEC in smoker and non-smoker, in the form of bar diagram

Table 4: Comparison of Blood lead level of LEBW and NLEC in drinker and non-drinker

\begin{tabular}{|l|l|l|l|}
\hline \multirow{2}{*}{ Variable } & LEBW & NLEC & \multirow{2}{*}{ P - Value } \\
\cline { 2 - 4 } & Mean \pm SD & Mean \pm SD & \\
\hline Drinker & $44.2 \pm 33.1$ & $14.7 \pm 7.7$ & 0.001 \\
\hline Non-drinker & $35.4 \pm 27.2$ & $6.3 \pm 5.8$ & 0.001 \\
\hline
\end{tabular}

LEBW = lead exposed battery workers

NLEC $=$ Non lead exposed controls

Values in Mean \pm SD

$* \mathrm{p}<0.001$ (highly significant)

This was observed that the average (Mean \pm SD) Blood lead concentration in drinkers and non-drinkers of LEBW group, that was found in LEBW in the drinkers was $44.2 \pm 33.1$ and non-drinkers was $35.4 \pm$ 27.2. Drinkers showed significantly higher blood lead level as compare to non-drinkers in the battery workers, with a p value of $<0.001$. However, one way anova of variance indicated that these differences in mean blood lead level among drinkers and non-drinkers is highly significant $(p<0.001)$. 


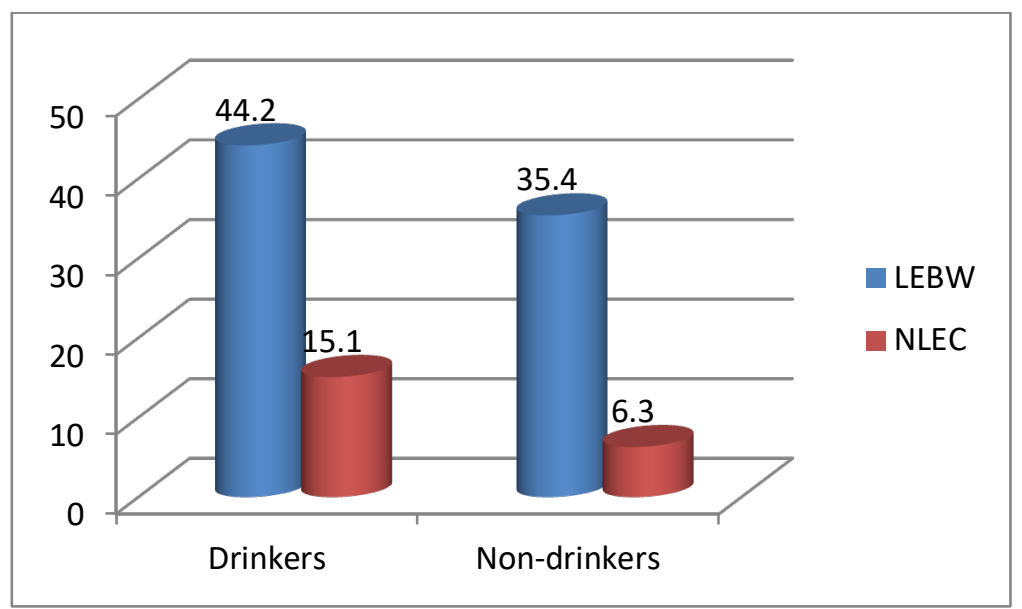

Figure 4: Comparison of Blood lead level of LEBW and NLEC in drinkers and non-drinkers, in the form of bar diagram

Table 5: Comparison of Vitamin D3 level of LEBW and NLEC

\begin{tabular}{|l|l|l|l|}
\hline \multirow{2}{*}{$\begin{array}{l}\text { Variable } \\
(\mathbf{n g} / \mathbf{m L})\end{array}$} & LEBW & NLEC & \multirow{2}{*}{ P - Value } \\
\cline { 2 - 3 } & Mean $\pm \mathbf{S D}$ & Mean $\pm \mathbf{S D}$ & \\
\hline Vitamin D3 & $17.8 \pm 9.1$ & $52.1 \pm 12.3$ & 0.001 \\
\hline
\end{tabular}

LEBW $=$ lead exposed battery workers

NLEC $=$ Non lead exposed controls

Values in Mean \pm SD

$* \mathrm{p}<0.001$ (highly significant)

This was observed that the average (Mean \pm SD) Vitamin D3 concentration that was found in the LEBW group was $17.8 \pm 9.1$ and in the NLEC group, it was $52.1 \pm 12.3$. The Vitamin D3 level was found significantly lower in LEBW group, in comparison to that in the (NELC group) control group, with a $p$ value of $<0.001$. However, one-way anova of variance indicated that these differences in mean Vitamin D3 among two groups were highly significant $(p<0.001)$.

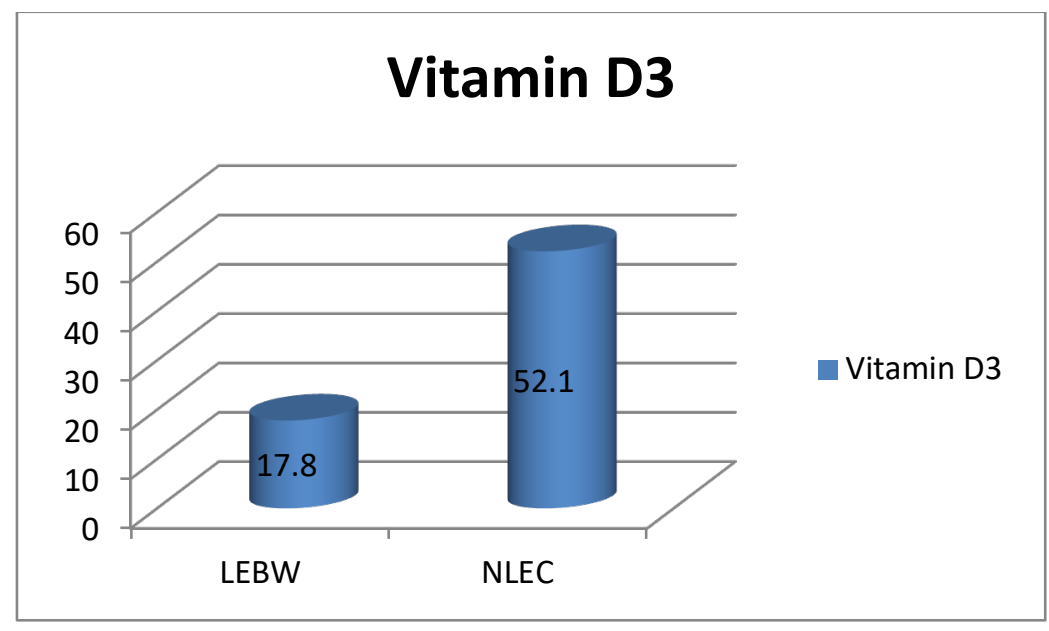

Figure 5: Comparison of vitamin D3 level of control group and subject group, in the form of bar diagram. 
Table 6: Comparison of serum calcium \& phosphorous level of LEBW and NLEC

\begin{tabular}{|l|l|l|l|}
\hline \multirow{2}{*}{$\begin{array}{l}\text { Variable } \\
(\mathbf{m g} / \mathbf{d l})\end{array}$} & LEBW & NLEC & \multirow{2}{*}{ P - Value } \\
\cline { 2 - 4 } Calcium & Mean \pm SD & Mean \pm SD & 0.001 \\
\hline Phosphorous & $7.6 \pm 0.6$ & $9.9 \pm 0.9$ & 0.001 \\
\hline
\end{tabular}

LEBW $=$ lead exposed battery workers

NLEC $=$ Non lead exposed controls

Values in Mean \pm SD

$* \mathrm{p}<0.001$ (highly significant)

Table 6: Shows statistical analyzes projected that the serum calcium \& phosphorous of lead exposed battery workers found to be significantly lower. This was observed that the average (mean \pm SD) serum calcium \& phosphorous concentration that was found in the LEBW group was 7.6 \pm 0.6 and $2.1 \pm 0.7$ and in the NLEC group, it was $9.9 \pm 0.9$ and $4.2 \pm 1.2$. The serum calcium $\&$ phosphorous level was found to be significantly low in comparison to that in the control group, with a $p$ value of $<0.001$. However, oneway anova of variance indicated that these differences in mean serum calcium \& phosphorous among two groups were highly significant $(\mathrm{p}<0.001)$.

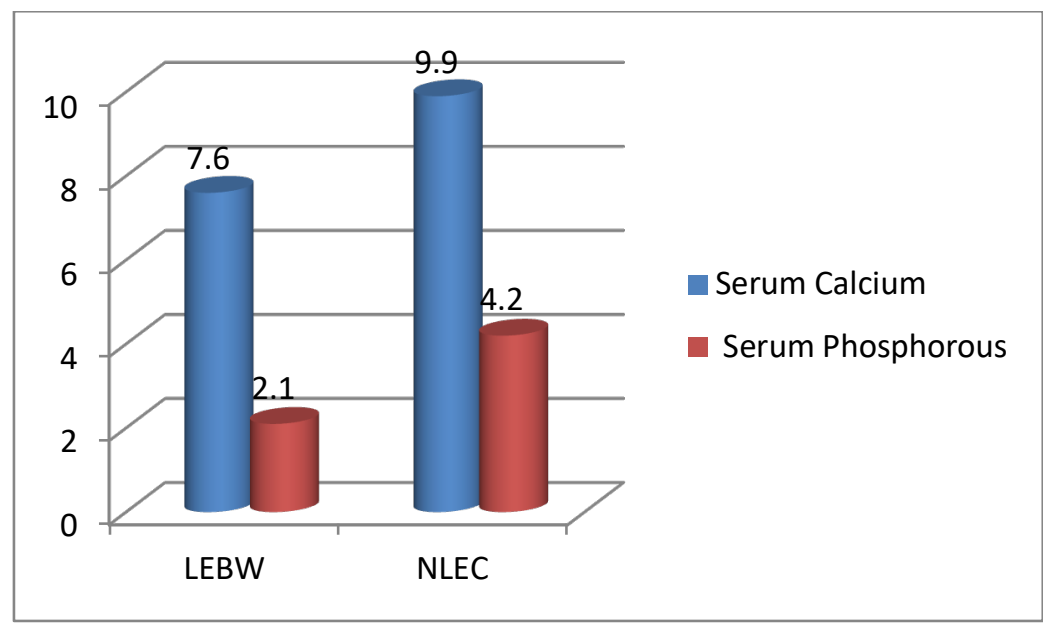

Figure 6: Comparison of serum calcium \& phosphorous level of control group and subject group, in the form of bar diagram.

\section{Discussion}

The blood lead level was found significantly higher in lead exposed battery workers, in comparison to that in the non-lead exposed controls group, with a $p$ value of $<0.001$. The serum calcium \& phosphorous level and Vitamin D3 level was found significantly lower in LEBW group, in comparison to that in the (NELC group) control group, with a $p$ value of $<0.001$. We also found smokers showed significantly higher blood lead level as compare to non-smokers in the battery workers and Drinkers showed significantly higher blood lead level as compare to non-drinkers in the battery workers. These findings were concordant with the results of the studies, which were previously done by Batra et al., (2020), Himani et al., (2020) and Ahmad et al., (2018) found that the BLL were substantially greater in LEBW than $\operatorname{NLEC~(p~0.0001)~})^{7,8,9}$.

In present study, we discovered a link between blood lead levels and lead exposure length, serum vitamin D, serum calcium, serum phosphorus levels, Fok1, and Bsm1 polymorphisms in our study. In battery production workers, blood calcium, serum phosphorus, and serum vitamin D levels were all significantly lower. This decrease in serum calcium could be linked to an increase in 
BLL, which has been demonstrated to disrupt the enzyme 1-- hydroxylase, which is required for calcitriol formation in the body. Calcitriol maintains calcium and phosphorous balance by stimulating the formation of calcium binding protein in the small intestine, which promotes calcium absorption across the small intestine. Calcium and phosphorus absorption across renal tubules is also influenced by calcitriol. As a result, higher BLL levels may have resulted in lower vitamin D levels, which in turn resulted in lower calcium and phosphorous levels in the blood in this investigation.

\section{Conclusion}

The blood lead level in lead-exposed battery workers was found to be considerably higher than in non-exposed controls. Furthermore, it was discovered that blood lead levels varies significantly with increasing age and duration of exposure in lead-exposed battery workers when they were divided by age and duration of exposure.

In comparison to non-exposed controls, leadexposed battery workers had considerably lower serum vitamin D, serum calcium, and serum phosphorus levels.

In lead-exposed battery workers, correlation analysis revealed a strong negative connection between blood lead levels and serum vitamin D levels. Similarly, serum calcium levels were found to be inversely linked with blood lead levels.

\section{References}

1. Agency for Toxic Substances and Disease Registry (ATSDR). Toxicology profilr for lead,USDepartment of health and human services. Atlanta, Georgia, USA:US Government Printing,2005; pp 102-225.
2. Patel AB, Williams SV, Frumkin H. blod lead in children and its determinants in Nagpur, India. Int. J Occup Environ Health 2001;7:11926.

3. Ibiebele DD. Air and blood lead levels in a battery factory. Sci Total Environ 1994; 152(3):269-73.

4. Tang HW, Liang YX, Hu XH and Yang HG. Alterations of monoamine metabolites and neurobehavioral function in lead exposed workers. Biomed Environ Sci 1995; 8(1):23-9.

5. Raafat BM, Hassan NS and Aziz SW.Bone mineral density (BMD) and osteoporosis risk factor in Egyptian male and female battery manufacturing workers. Toxicol Ind Health 2012; 28(3):245-52.

6. Schwartz BS, Stewart WF, Kelsey KT, Simon D, Park S, Links JM et al. Associations of tibial lead levels with Bsml polymorphisms in the vitamin D receptor in former organolead manufacturing works. Environ Health Perspect 2000; 108:199-203.

7. Batra J, Thakur A, Meena SK, Singh L, Kumar J, Juyal D. Blood lead levels among the occupationally exposed workers and its effect on calcium and vitamin D metabolism: A casecontrol study. J Family Med Prim Care. 2020; 9(5):2388-93.

8. Himani, Kumar R, Ansari JA. et al. Blood Lead Levels in Occupationally Exposed Workers Involved in Battery Factories of Delhi-NCR Region: Effect on Vitamin D and Calcium Metabolism. Ind J Clin Biochem 2020; 35:80-87.

9. Ahmad I, Khan B, Khan S, Khan MT, Schwab AP. Assessment of lead exposure among automobile technicians in Khyber Pakhtunkhwa, Pakistan. Sci Total Environ. 2018; 633:293-9. 